\title{
Oncological Scenario in Developing Countries - Little Light at the End of Tunnel
}

\author{
Lt Col Virender Suhag, Lt Col Sunita BS and Lt Col Manu Chopra \\ Army Hospital (R\&R), Delhi, India
}

\section{Keywords}

Advanced cancer, developing countries, high mortality \& morbidity, lack of facilities, palliative care, united efforts

Disclosure: Virender Suhag, Sunita BS and Manu Chopra have nothing to disclose in relation to this article. No funding has been received for the publication of this article. This article is a short opinion piece and has not been submitted to external peer reviewers.

Authorship: All named authors meet the International Committee of Medical Journal Editors (ICMJE) criteria for authorship of this manuscript, take responsibility for the integrity of the work as a whole, and have given final approval to the version to be published.

open Access: This article is published under the Creative Commons Attribution Noncommercial License which permits any non-commercial use, distribution, adaptation and reproduction provided the original author(s) and source are given appropriate credit.

Received: 13 February 2017

Published Online: 31 March 2017

Citation: European Oncology \& Haematology,

2017;13(1):13-4

Corresponding Author: Virender Suhag, Dept of Radiation Oncology, Army Hospital (R\&R), Delhi, India. E: virendersuhag@gmail.com
The incidence and prevalence of most cancers is increasing worldwide because of the aging population, increased prevalence of established risk factors with urbanisation and economic development and changing social and demographic trends including late marriage and fewer child-births. Based on GLOBOCAN and International Agency for Research on Cancer (IARC) estimates, about 14.1 million new cancer cases and 8.2 million deaths occurred in 2012 worldwide, this figure is expected to grow to 21.7 million new cancer cases and 13 million cancer deaths by 2030. ${ }^{1}$ Globally, the cancer burden is gradually shifting to developing and under-developed world, which currently account for about $57 \%$ of new cases and $65 \%$ of cancer deaths worldwide. ${ }^{12}$ However, the oncology scenario in most developing countries is still dismal, plagued by lack of screening, delayed diagnosis, long travel time to cancer hospital, shortage of cancer centres, poor infrastructure, outdated technology, manpower crunches, long waiting lists, lack of accommodation for outstation patients, lack of affordability and apathy of government agencies. With regard to India, from an estimated incidence of 1.45 million cases in 2016, the cancer incidence is expected to reach 1.75 million cases in $2020 .^{3}$ It is estimated that about $70-80 \%$ of these cancers present are at stage III and IV resulting in high mortality rate. An estimated 600,000-700,000 deaths in India were caused by cancer in 2012.,5

Most of the government hospitals and medical colleges in these developing countries are battling with outdated poorly-maintained radiotherapy machines which require immediate replacement. Most of these countries have one machine for several million people with huge deficiency of trained manpower, and telecobalt units continue to be the main workhorse rather than the linear accelerators. ${ }^{6}$ Such heavy workload compromises the quality assurance and preventive maintenance of these machines. Though economy in few developing countries is trending upwards, the governments are hardly spending anything on healthcare. The expenditure on healthcare in India in 2015 and 2016 by the centre and state governments was 1.3\% of the GDP (Anupriya Patel, Minister of State for Health and Family Welfare, statement to Media). Moreover, the process of up-gradation and modernisation in public sector is long, tedious and complicated by unhealthy competition between the limited number of vendors and corruption in various procuring agencies. There is urgent need to develop affordable, low-maintenance, indigenous machines best suited to Indian requirements. Some progress has already been made in this regard, though there is still tremendous scope of improvement and various public labs, apex medical research institutes and other government agencies involved in research and development should join hands to make more medical linear accelerators and install them in smaller cities.?

There is great diversity between the oncology facilities available to different strata of society. The privileged ones from affluent class, which constitute a minor part of overall population, have access to the newly commissioned multi-specialty corporate hospitals in urban metropolitan cities. These centres are equipped with state-of-art imaging tools and linear accelerators compatible with highly conformal radiotherapy. However, the majority of patients from lower and middle socio-economic strata do not have access to such facilities due to poor affordability, as most of the medical linear accelerators are imported and treatment is quite costly. These patients are treated in peripheral centres in public setup, most of which are ill-equipped with 
poor quality assurance and lack of skilled manpower. Few apex tertiary care hospitals in public sector are also well-equipped, but suffer from huge workload and long waiting lists for routine patients. Availability of chemotherapy drugs in regional cancer centres is not consistent, leading to frequent interruption of treatment. The situation is further complicated by unavailability of paediatric and geriatric oncologists, as patients in this bracket have got special needs. Unfortunately, there are a lack of emotional counsellors, bereavement services and support groups in most cancer hospitals in public sector.

About $80 \%$ of the cases in India will merit palliative care during the final course of their disease, and unfortunately, there is an acute shortage of palliative care centres in India. Due to the scarcity of beds in most cancer hospitals, and for optimum utilisation of existing resources, there is a reluctance to admit patients for terminal care. The general practitioners lack the skills of optimum management of chronic pain. There is frequently poor availability of opioids because they are controlled substances and closely regulated by national and international laws. There are frequently restrictions that limit who may stock and prescribe these medications, and also on the quantity that can be given per prescription. Use of opioids is also restricted by fears regarding addiction by governments and the physicians alike. Key barriers related to palliative care include poor perception and evaluation of pain, lack of skilled manpower and pain clinics, opioid misperceptions, bureaucratic hurdles and sociocultural challenges. Moreover, most insurance schemes don't cover palliative care. Most of such patients receive best supportive care at home. This is not only emotionally exhausting for the family members but also involves considerable financial burden. The family physicians and the paramedical staff proving community care should be familiarised with basic skills of palliative care.8-10

Since these patients present in locally advanced stage with compromised nutritional and performance status, they are likely to develop therapyinduced site-specific and systemic toxicities and may require emergency hospitalisations and treatment interruptions, which not only lead to costescalation of management, but may also lead to suboptimal oncological outcome and hence grim prognosis. Another worrisome factor involved is acute shortage of critical care beds in the intensive care unit (ICU) for cancer patients when they develop treatment induced or disease-related complications. Instead of giving a blanket refusal to these patients, every hospital should have a departmental protocol where the intensivist does the triage, and manage the salvageable cases in collaboration with the oncologists. Another key reason for the poor oncology scenario in India is the high proportion of out-of-pocket expenditure (up to 70\%) on health because of low insurance coverage and weak public health systems. Only about $15 \%$ of the country's population is covered by some form of health insurance. The good news is that the penetration of the health insurance market has been increasing over the years; it has been one of the fastest growing segments of business in India. Government should ensure that the insurance players in the private sector do not suffer bureaucratic hurdles.

Many developing countries also lack proper population-based cancer registries and the statistics are based largely on figures from noncomprehensive hospital-based registries, which are often incomplete, unrealistic, poorly-maintained and suffer from under reporting. The data is underreported and may be just the tip of iceberg. There is little scope of authentic research or formulation of health-policies based on this data. Most of the patients do not enrol in trials. Most of the oncologists follow universal guidelines established by developed countries. Patients in developing countries have different disease biology, etiopathogenesis, performance status, as compared to their counterparts in the developed world, and thus need to be managed differently by individually-tailored approach.

In this journey called life, while some of us are fortunate enough to write and read such opinion articles, there is a vast sea of unprivileged population battling with cancer and hardly any means to manage it. Helping them is not only humane and desirable, but also a mandatory requirement to make this world a better place and to prevent the loss of a huge working class. It is high time the entire world unites and put a big united fight against cancer. $\square$
1. Antoni S, Soerjomataram I, Møller B, et al., An assessment of GLOBOCAN methods for deriving national estimates of cancer incidence, Bull World Health Organ, 2016;94:174-84.

2. Torre LA, Bray F, Siegel RL, et al., Global cancer statistics 2012, CA Cancer J Clin, 2015;65:87-108.

3. Gandhi AK, Kumar P, Bhandari M, et al., Burden of preventable cancers in India: Time to strike the cancer epidemic, J Egypt Natl Canc Inst, 2016; [Epub ahead of print].

4. Khosla D, Patel FD, Sharma SC, Palliative care in India: current progress and future needs, Indian I Palliat Care, 2012:18:149-54. 5. Mallath MK, Taylor DG, Badwe RA, et al., The growing burden of cancer in India: epidemiology and social context, Lancet Oncol, 2014;15:e205-12.

6. Zubizarreta EH, Fidarova E, Healy B, et al., Need for radiotherapy in low and middle income countries - the silent crisis continues, Clinic Oncol, 2015;27:107-14.

7. Kumar RV, Bhasker $\mathrm{S}$, Is the fast-paced technological advancement in radiation treatment equipment good for Indian
Scenario? Journal of Cancer Policy, 2015:4:26-30.

8. Kar SS, Subitha L, Iswarya S, Palliative care in India: Situation assessment and future scope, Indian I Cancer, 2015;52:99-101.

9. Bandewar SV, Access to controlled medicines for palliative care in India: gains and challenges, Indian J Med Ethics, 2015;12:77-82

10. Lebaron V, Beck SL, Maurer M, et al., An ethnographic study of barriers to cancer pain management and opioid availability in India, Oncologist, 2014;19:515-22. 